\title{
Deteç̧ão de mudanças na cobertura vegetal da bacia hidrográfica do Rio Inhaúma - PE/AL, por meio de técnicas de Geoprocessamento e dados de Sensoriamento Remoto
}

\author{
Detection of changes in vegetation of the watershed of Inhaúma - PE / AL, through GIS \\ techniques and remote sensing data
}

\author{
LIMA $^{1}$, C. E. S.; GOMES ${ }^{2}$, D. D. M.; GOLDFARB ${ }^{3}$, M. C.
}

carloslima.geo@gmail.com;

\begin{abstract}
Resumo
O presente trabalho teve como objetivo apresentar um relato das transformações na cobertura de vegetação da Bacia Hidrográfica do Inhaúma - PE/AL, analisando de forma multitemporal suas transformações nos períodos de 1992 a 2011. Para esta análise robusta, foi necessário o uso de dados espectrais obtidos pelo sensor remoto TMLandsat 5, que, conjuntamente de um ambiente computacional ArcGis 10.4.1, através do software foram realizados os cálculos (NDVI - Normalized Difference Vegetation Index). Com os dados gerados, foi possível desenvolver uma classificação supervisionada da vegetação, para esta classificação foram utilizadas quatro classes: vegetação densa, vegetação esparsa, vegetação rasteira e ausência de vegetação. Após a classificação, foram realizados mapas temáticos, que forneceu uma análise comparativa, entre 1992 e 2011, tendo assim uma melhor perspectiva das mudanças durante 19 anos. Com a análise, pode-se provar um decréscimo acentuado na vegetação densa, de $2,19 \%$ para $1,81 \%$, com a classe esparsa caiu de $26,74 \%$ para $24,02 \%$, na classe rasteira $67,43 \%$ para $55,9 \%$, na ausência de vegetação foi de $3,74 \%$ para $18,36 \%$. Com a análise foi capaz de detectar a substituição da classe: vegetação densa para vegetação rasteira e ausência de vegetação.
\end{abstract}

Palavras-chave: Bacia Hidrográfica do Inhaúma, Cobertura Vegetal, Geotecnologias.

\begin{abstract}
This study aimed to present an account of the changes in the Basin vegetation cover Inhaúma - PE / AL, analyzing multitemporal form their transformations in the period 1992-2011, for this robust analysis, the use of spectral data was necessary obtained by remote sensing TMLandsat 5, which together a ArcGis 10.4.1 computing environment through software calculations were made (NDVI - Normalized Difference Vegetation Index). With the data generated, it was possible to develop a supervised classification of vegetation, for this classification four classes were used: dense vegetation, sparse vegetation, underbrush and lack of vegetation. After classification, they were carried out thematic maps, which provided a comparative analysis between 1992 and 2011, thus having a better perspective of the changes for 19 years. With the analysis, one can prove a marked decrease in the dense vegetation of $2.19 \%$ to $1.81 \%$, with the sparse class fell from $26.74 \%$ to $24.02 \%, 67.43 \%$ in undergrowth class to $55.9 \%$, in the absence of vegetation was $3.74 \%$ to $18.36 \%$. With the analysis was able to detect the replacement class: dense vegetation to scrub and lack of vegetation.
\end{abstract}

\section{INTRODUÇÃO}

A vegetação possui uma grande importância para a manutenção dos sistemas ambientais, a cobertura vegetal tem a funcionalidade de interceptar as gotas de chuva, reduzindo a velocidade das mesmas, diminuindo então, os danos causados pelo gotejamento, entre eles a erosão, proporcionado pelo splash, que pode ser definido; como o efeito de gotejamento das águas da chuva, que atingem os solos desnudos,

${ }^{l}$ Carlos Eduardo Santos de Lima, Geografia / Geoprocessamento e Modelagem Ambiental, Universidade de Pernambuco, Garanhuns-PE, Brasil.

${ }^{2}$ Daniel Datnas Moreira Gomes, Geografia / Geoprocessamento e Modelagem Ambiental, Universidade de Pernambuco, Garanhuns-PE,

${ }^{3}$ Maurício Costa Goldfarb, Matemática / Geoprocessamento e Modelagem Ambiental, Universidade de Pernambuco, Garanhuns-PE, Brasil. 
com a violência da força cinética, compactando o corpo do solo, e desintegrando os grânulos do mesmo, passando de um corpo homogêneo, para heterogêneo, e sendo transportados para depressões, tendo então uma erosão laminar.

Para Drew (1983) com a ausência da cobertura vegetal, ausência de plantação agrícola e florestas regeneradas, é causado um grande pico fluvial, e tendo como consequências grandes estragos na foz do rio. Para Troppmair (2008), a erosão depende do tipo de solo e da cobertura vegetal que está presente na bacia hidrográfica.

Para a análise da cobertura vegetal, foram utilizadas técnicas de Geoprocessamento e de Sensoriamento Remoto. Estas, estão cada vez mais presentes nos trabalhos acadêmicos, como nos artigos de periódicos, dissertações de mestrado e, em teses de doutorado. As referidas técnicas, possuem um potencial ímpar, possibilitando diversas análises. O Geoprocessamento pode ser definido como uma técnica computacional, que gera e manipula dados georreferenciados, cuja a utilização dessas técnicas foca em realizar aquisição, manipulação, transformação, espacialização e referenciamento de dados. Fitz (2008) defini como; o conjunto de programas computacionais, que integra dados, sendo possível a manipulação, armazenamento, coleta, visualização e transformação dos mesmos em dados cartograficamente referenciados em uma projeção conhecida.

Câmara, Davis e Monteiro (2015) complementam que o Geoprocessamento se utiliza das técnicas matemáticas e computacionais, e com seus avanços e disponibilidade no mercado vem influenciando áreas como a Cartografia, Planejamento Urbano e Regional, Planejamento Energético, Comunicações, Transportes, e Análises dos Recursos Naturais, entre outros.

Já, o Sensoriamento Remoto, é considerado como uma das ferramentas mais completas, ao que se refere na extração, compreensão e análise dos recursos da natureza. Esta ferramenta é poderosa e robusta, permitindo-nos uma visualização sintética do planeta Terra, deste modo alcançando locais de difícil acesso entre outros (GOMES, 2010, 2011, 2015). Rosa (2009) compreende o sensoriamento remoto como, a forma de obter informações sem que haja o contato físico com o alvo em questão. $\mathrm{O}$ mesmo salienta sobre o funcionamento do sensor remoto, informando que o sistema para obter as informações é realizado pela radiação eletromagnética, gerada então, pelo Sol, ou por sensores que emitem ondas eletromagnéticas, como o radar.

Em virtude da diminuição da cobertura vegetal, foi proposto uma análise multitempol da bacia hidrográfica do Inhaúma - PE/AL, sendo possível apenas com a utilização de dados espectrais e hiperespectrias, advindos do sensoriamento remoto. Os dados obtidos pelo sensor remoto TM/Landsat 5, foram adquiridos como um parâmetro para análises das condições dos recursos florestais do município.

Para a análise do estado da cobertura vegetal, foi utilizado o NDVI - Normalized Difference Vegetation Index, que é um índice de vegetação, realizados através de técnicas de geoprocessamento, que realiza o realce da biomassa da bacia em análise. $\mathrm{O}$ mesmo vem se tornando uma prática corriqueira no meio acadêmico e no meio corporativo, pois este índice permite um robusto monitoramento da cobertura 
vegetal, permitindo então uma tomada de decisão ao que concerne o estado e conservação da cobertura vegetal e os recursos naturais, (PONZONI, SANTOS e CANTINHO, 2013).

Tendo então, como objetivo principal deste trabalho, o monitoramento das transformações na cobertura vegetal da Bacia Hidrográfica do Inhaúma - PE/AL, analisando de forma multitemporal, observando e registrando as etapas de transição. As análises realizadas foram fomentadas pelos seguintes anos, 1992 e 2011.

\subsection{LOCALIZAÇÃO DO OBJETO DE ESTUDO}

A Bacia hidrográfica do Inhaúma está inserida em dois estados, Pernambuco e Alagoas, como pode ser visto na (Figura 01), entre as coordenadas, 36 26' 0"'/36 $6^{\circ} 30^{\prime}$ ' de Longitude Oeste, e entre as coordenadas $9^{\circ}$ 4' $0^{\prime}, / 8^{\circ} 53$ ' 0 " de Latitude Sul. A referida bacia hidrográfica abarca cerca de 8 municípios brasileiros. A sudeste do estado de Pernambuco, com 6 municípios, que são eles: Angelim, Canhotinho, Correntes, Garanhuns, Palmeirina e São João. Já à nordeste do estado de Alagoas, há apenas dois municípios, que compreende a bacia, são eles: Santana do Mundaú e São José da Laje. A bacia hidrográfica totaliza uma extensão territorial de aproximadamente $452,41 \mathrm{Km}^{2}$.

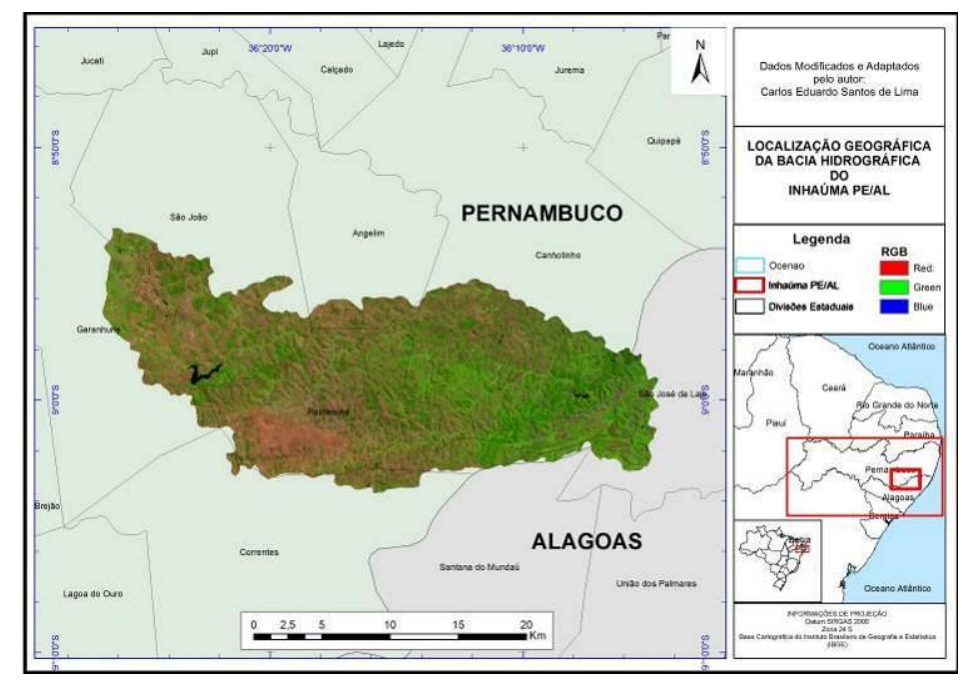

Figura 01. Localização da Bacia Hidrográfica do Inhaúma - PE/AL. Fonte: Adaptado pelos autores.

\section{METODOLOGIA}

\subsection{Dados Orbitais}

Para a realização da presente pesquisa, foram utilizados dados orbitais do objeto de estudo. As imagens foram adquiridas através do Instituto Nacional de Pesquisas Espaciais - (INPE), disponibilizadas gratuitamente pelo catálogo de imagens no site www.inpe.br e da United States Geological Survey - 
(USGS), através do site http://earthexplorer.usgs.gov. O Sensor Remoto utilizado foi o TM - LANDSAT 5, as imagens utilizadas, tem como referências a órbita 214, ponto 66, e zona 24 Sul.

\subsection{Procedimentos Metodológicos}

Para a realização da presente pesquisa, foi seguido uma metodologia que está presente em 14 etapas. A primeira etapa consiste na escolha do objeto de estudo. A segunda etapa concerne no levantamento cartográfico, assim obtendo todos os dados pertinentes a cartografia da bacia em análise. A terceira etapa refere-se no reconhecimento da bacia, desta forma foi possível a realização, quantificar a sua extensão, e identificar a sua real posição geográfica. A quarta etapa, consiste na atividade de campo, levantamento bibliográfico e a delimitação da área da bacia em análise. Na quinta etapa, foi fomentado o BD - banco de dados. A sexta etapa, refere-se à padronização do banco de dados da pesquisa, desta forma é possível minimizar os erros cartográficos. A sétima etapa da metodologia, é consistida no PDI - Processamento Digital de Imagens.

A oitava etapa, concerne no fomento da equação do NDVI, demonstrado logo abaixo, na equação (1).

\section{IVP - V}

IVP + V

Após a realização da equação acima, as imagens geradas variam de - 1, que é um indicador da ausência da biomassa, e o +1 , indica a biomassa saldável, com as folhas verdes e com um teor hídrico considerável nas folhas, conforme pode ser observado logo abaixo, na (Figura 02).

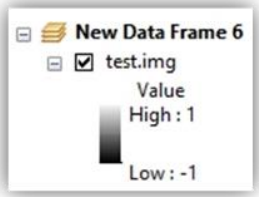

Figura 02. Variação Numérica da Imagem de NDVI, -1 ausência total de vegetação e,+1 , vegetação sadia e verde. Fonte: Adaptado pelos autores.

As imagens de NDVI variam em tons de cinza, conforme a (Figura 03) da Bacia Hidrográfica do Inhaúma - PE/AL, logo abaixo: 


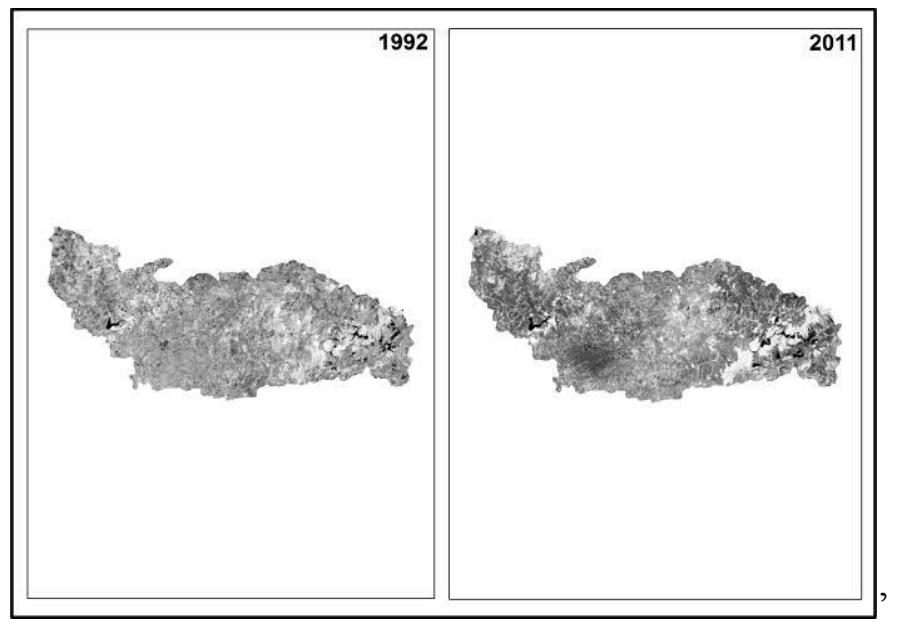

Figura 03. Análise comparativa das imagens de NDVI, nos anos de 1992 e 2011. Fonte: Adaptado pelos autores da plataforma ArcGis 10.4.1

A nona, é referida na segmentação das imagens de NDVI, esta etapa é caracterizada pelo agrupamento dos pixels. A décima etapa, refere-se à classificação supervisionadas das imagens de NDVI, segmentada. A décima primeira etapa consiste na análise da classificação supervisionada e do mapeamento das classes obtidas. A décima segunda etapa refere-se à quantificação dos dados gerados, e a visitas ao campo, para verificar a veracidade da classificação.

$\mathrm{Na}$ etapa de campo, é onde se torna possível identificar a veracidade da classificação supervisionada realizada no Software ArcGis 10.4.1. Em campo, foram realizadas várias paradas conforme a (Figura 04), para a captura de imagens através de uma câmera, e marcação de alguns pontos considerados como relevantes para demonstração. Em campo, pudemos constatar os fenômenos de erosão, e principalmente a erradicação da cobertura vegetal densa, que foi classificada como resquício de mata atlântica.

No campo, é claro a substituição da cobertura vegetal densa, pelos loteamentos que são vendidos nos municípios que fazem parte da bacia hidrográfica, em maior grau de desmatamento para a realização de loteamentos podemos citar Garanhuns e São João. Há ainda, uma grande plantação, estas são as lavouras e pastagens para a alimentação dos gados das fazendas que estão inseridos nos municípios que compõe a referida bacia hidrográfica, esta ação de pastagem está presente em todos os municípios visitados em campo, a agricultura e a pecuária é muito forte nestes municípios.

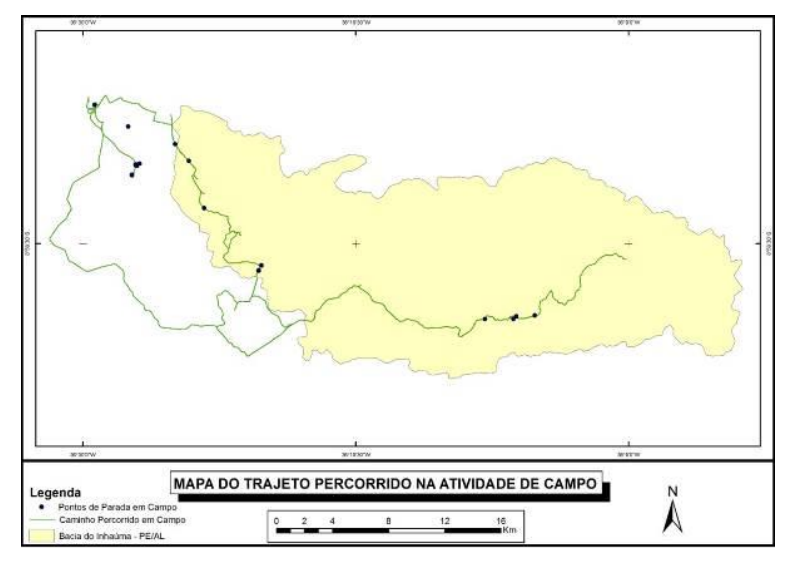


Figura 04. - Mapa da Trajetória percorrida em Campo, na Bacia do Inhaúma PE/AL. Fonte: Adaptado pelos autores.

Décima terceira etapa, pertinente à análise dos mapas, havendo a verificação de possíveis erros do analista. A décima quarta etapa, e a última, é referida à análise dos resultados e o término do artigo científico, conforme a (Figura 05) logo à baixo:

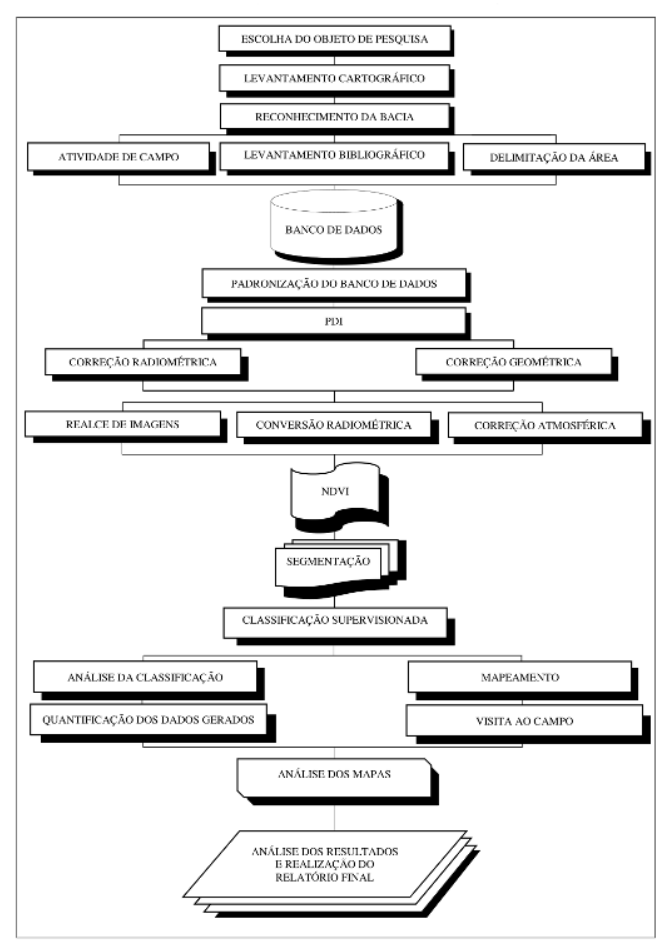

Figura 05. Fluxograma dos Procedimentos Metodológicos. Fonte: Adaptado pelos autores.

\section{RESULTADOS E DISCUSSÃO}

\subsection{Dados das Alterações da Cobertura Vegetal da Bacia Hidrográfica de Inhaúma - PE/AL}

\subsubsection{Análise dos dados da cobertura vegetal no ano de 1992}

Com o auxílio das técnicas de Geoprocessamento e dos dados do Sensor Remotos Landsat 5 TM, foi possível realizar as devidas classificações da cobertura vegetal da referida Bacia Hidrográfica. A partir, da realização da classificação supervisionada das imagens de NDVI, foram confeccionados mapas da cobertura vegetal da bacia hidrográfica do Inhúma - PE/AL, com os anos 1992 e 2011. Para os mapas foram estabelecidas quatro classes: Vegetação Densa, Vegetação Esparsa, Vegetação Rasteira e Ausência de Vegetação observada na (Figura 05).

$\mathrm{Na}$ (Tabela 1 e 2), podemos identificar e acompanhar a evolução das classes mapeadas. É possível notar no primeiro momento há diminuição da vegetação densa, que cai de uma área territorial de 9,91 $\mathrm{Km}^{2}$ para apenas $8,2 \mathrm{Km}^{2}$, tendo então uma perda de aproximadamente de $1,71 \mathrm{Km}^{2}$ da vegetação 
arbórea. Na classe denominada de Vegetação Esparsa, os números diminuem ainda mais, de uma área de $120,97 \mathrm{Km}^{2}$ cai para cerca de 108,66 Km² uma redução de $12,31 \mathrm{Km}^{2}$. Com a classe da Vegetação Rasteira representada pela agricultura e pelos pastos, houve um grande avanço ao que concerne a esta vegetação, no primeiro ano de análise era representada por apenas $305,05 \mathrm{Km}^{2}$, já no último ano de análise estes números são bastante expressivos, cerca de 252,91 $\mathrm{Km}^{2}$, representando um aumento de $52,14 \mathrm{Km}^{2}$. Ao que se refere a Ausência de Vegetação, classificados como o solo exposto, mancha urbana e a água, tivemos um acréscimo bastante expressivo, no primeiro ano de análise, a classe denominada de ausência de vegetação possuía uma área representativa de $16,91 \mathrm{Km}^{2}$, passando para um total de 83,08 $\mathrm{Km}^{2}$ de toda a área da bacia, representando um acréscimo de $66,17 \mathrm{Km}^{2}$, da área da bacia. Podemos então acompanhar todo o processo evolutivo da degradação da cobertura vegetal, através da representação cartográfica abaixo, na (Figura 06).

Tabela 01. Acompanhamento da degradação da cobertura vegetal da bacia hidrográfica do Inhaúma - PE/AL no ano de 1992 Fonte: Elaborado pelos autores.

\section{Níveis de Alterações 1992}

\begin{tabular}{c|c|c}
\hline Classes da Cobertura Vegetal & Área de Classes $\left.\mathbf{( K m}^{\mathbf{2}}\right)$ & Área em $\mathbf{( \% )}$ \\
\hline Vegetação Densa & 9,91 & 2,19 \\
\hline Vegetação Esparsa & 120,97 & 26,74 \\
\hline Vegetação Rasteira & 305,05 & 67,43 \\
\hline Ausência de Vegetação & 16,91 & 3,74 \\
\hline
\end{tabular}

Tabela 02. Acompanhamento da degradação da cobertura vegetal da bacia hidrográfica do Inhaúma - PE/AL no ano de 2011 Fonte: Elaborado pelos autores.

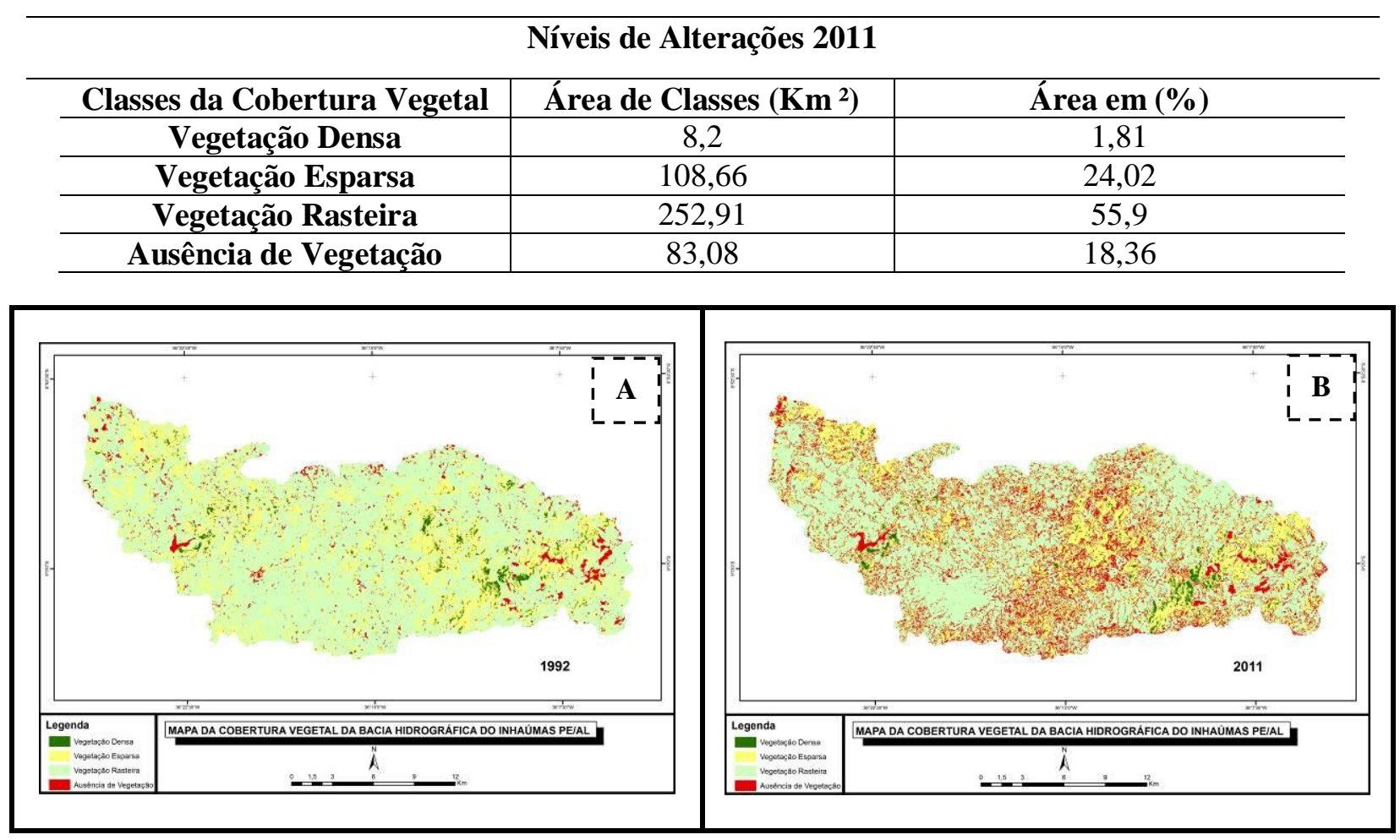


Figura 06. Representação da evolução e as modificações da cobertura vegetal através dos 19 anos da análise comparativa. Fonte: Elaborado pelos autores.

Com a quantificação dos dados gerados, foi possível identificar e demonstrar o grau de degradação da cobertura vegetal no referido ano, podemos visualizar na (Figura 06-A), na (Tabela 01) e na (Figura 07), a representação gráfica e quantitativa da bacia em análise no ano de 1992. Neste ano, a vegetação classificada como densa, possuía um total de 9,91 $\mathrm{Km}^{2}$, de uma área territorial de 452,41 $\mathrm{Km}^{2}$, representando então, cerca de 2,19 \% da extensão total da bacia. Na vegetação esparsa, foi identificado uma área de 120,97 $\mathrm{Km}^{2}$, representando cerca de $26,74 \%$ de toda a bacia. A vegetação rasteira, representado pela agricultura e pelos pastos, possuía cerca de $305,05 \mathrm{Km}^{2}$ de toda a área mapeada, representando então uma porcentagem elevada em relação as outras classes, cerca de $67,43 \%$ de toda área da bacia. Com os índices ainda em evolução, a ausência de vegetação, neste ano analisado é representado por números pouco avançados, cerca de $16,91 \mathrm{Km}^{2}$, com uma parcela percentual de apenas $3,74 \%$ de toda a área mapeada da bacia.

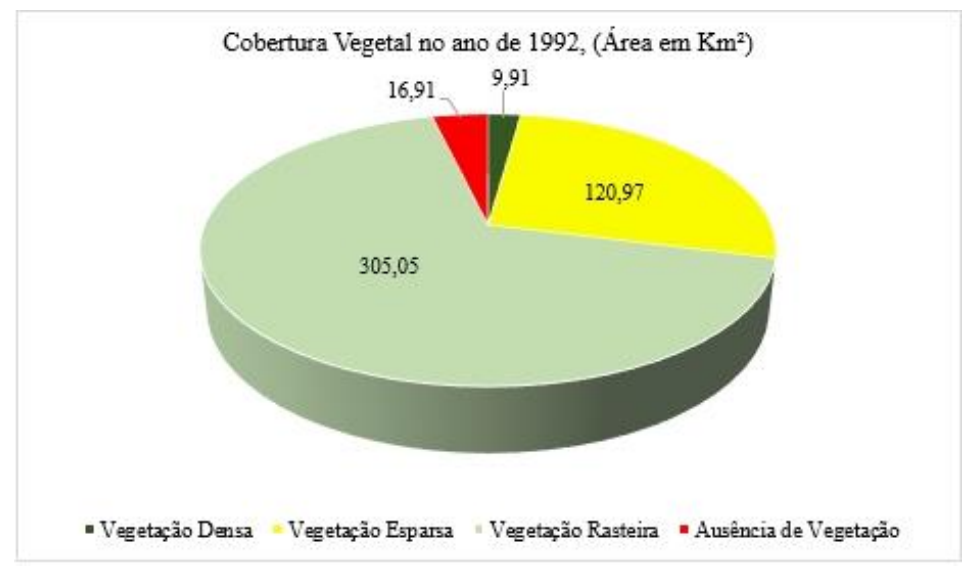

Figura 07. Representação Gráfica da área mapeada da Cobertura Vegetal de 1992. Fonte: Adaptado pelos autores.

\subsubsection{Análise dos dados da cobertura vegetal no ano de 2011}

Há grandes mudanças na cobertura vegetal da bacia hidrográfica do Inhaúma no ano de 2011. Visivelmente é possível percebermos a grande presença da cor vermelha em grande parte da bacia hidrográfica, indicador do forte desmatamento e do solo desnudo e/ou exposto, podemos visualizar o resultado na (Figura 06 B), na (Tabela 02) e na (Figura 08). Com a classe vegetação densa, foi mapeado uma área de apenas $8,2 \mathrm{Km}^{2}$, que representa um total de $1,81 \%$ de toda a área da bacia. Vegetação esparsa, no referido ano, a mesma possuía uma área de 108,66 $\mathrm{Km}^{2}$, representando uma percentagem de 24,02\%, de um total de área da bacia. Vegetação rasteira, esta classe é a que mais aumenta, juntamente com a ausência de vegetação, com um total de 252,91 Km² de uma área total da bacia de 452,41 Km², representando então um percentual de 55,9\%. Ausência de vegetação, no referido ano, esta classe possuía cerca de $83,08 \mathrm{Km}^{2}$, representando cerca de $18,36 \%$ de toda área da bacia. 


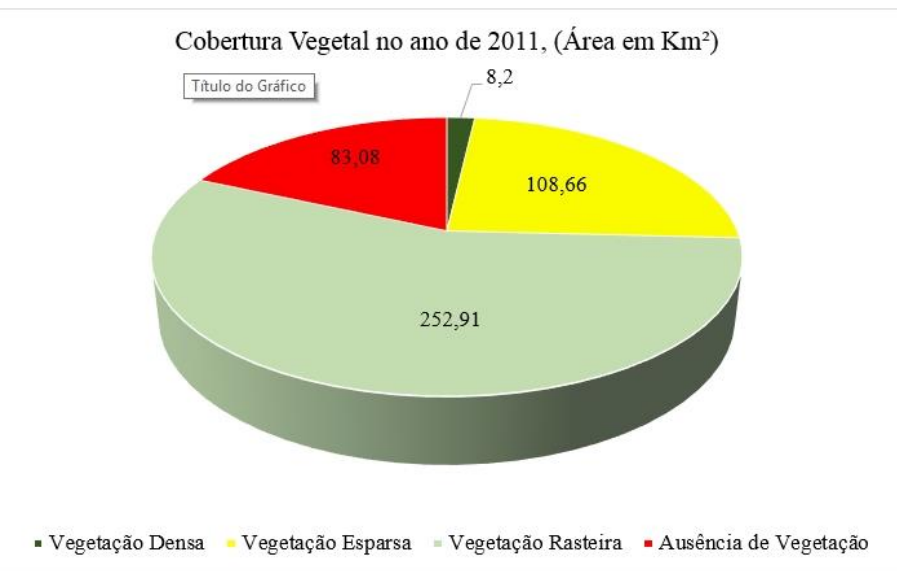

Figura 08. Representação Gráfica da área mapeada da Cobertura Vegetal de 2011. Fonte: Adaptado pelos autores.

\subsubsection{Trabalho de Campo, para identificação das Classes Estabelecida}

Após toda a classificação e o mapeamento, foi realizada atividade de campo, para identificar as classes estabelecidas no trabalho.

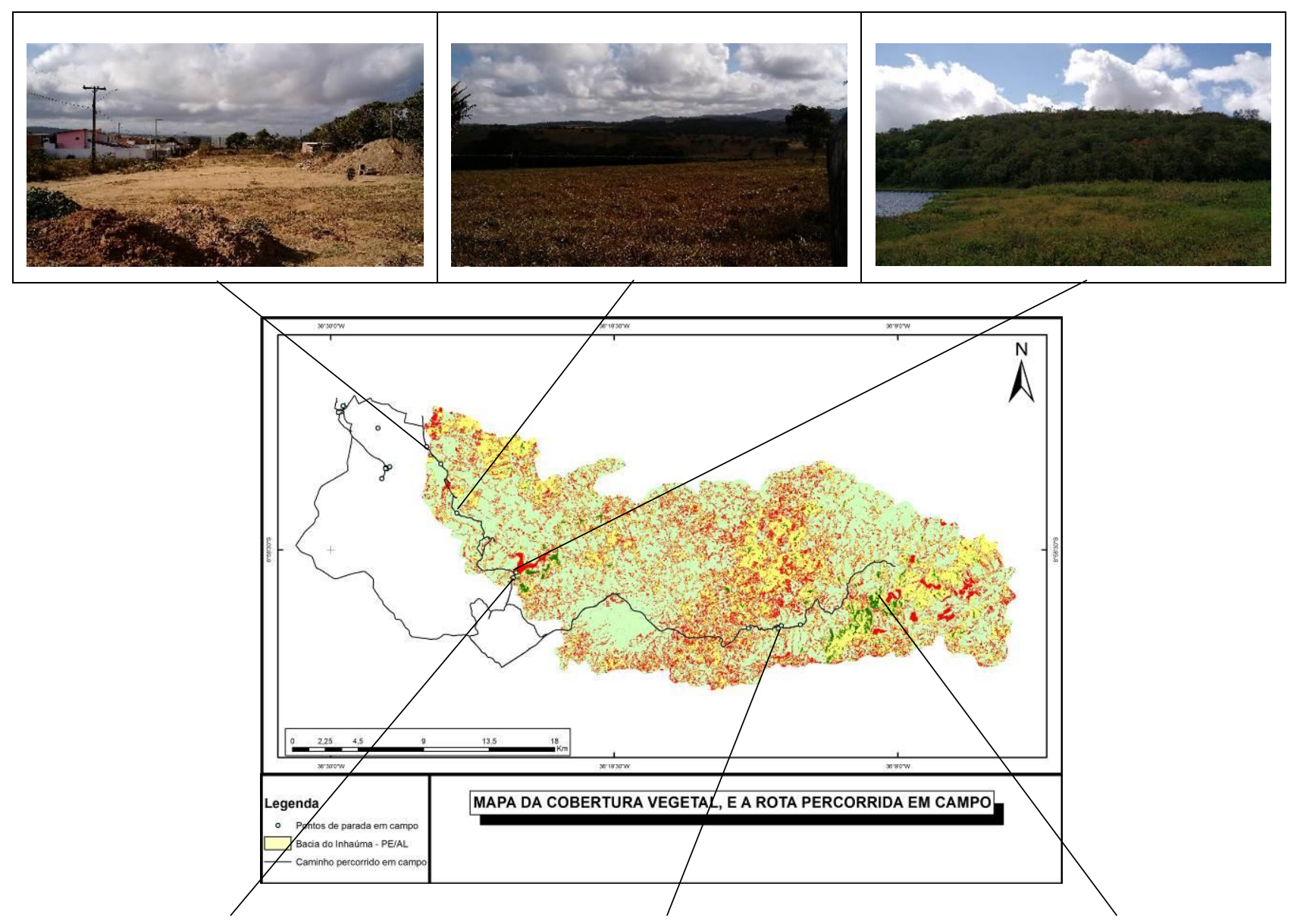




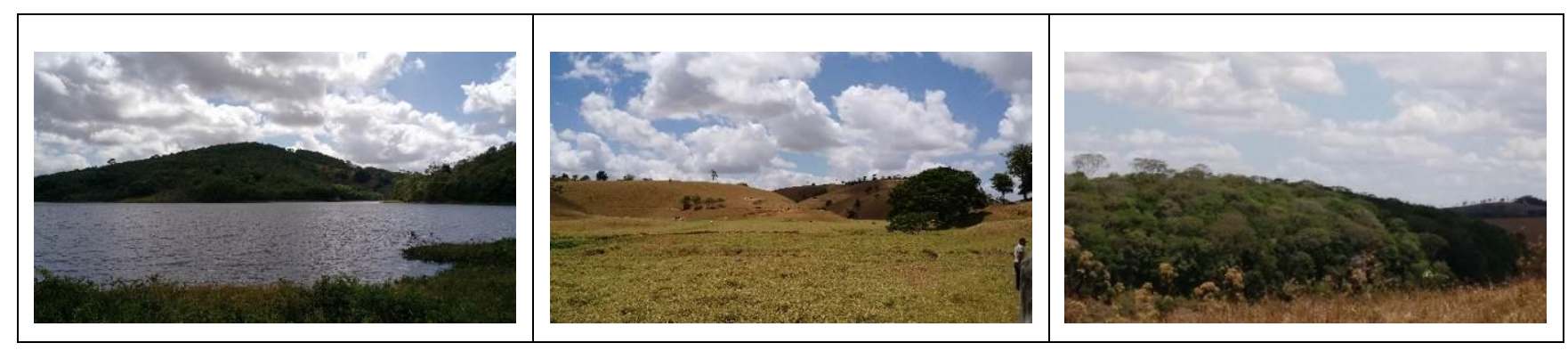

Figura 09. Mapa das paradas em campo, e retirada de fotografia, para veracidade da classificação. Fonte: Adaptado pelo autor.

\section{CONSIDERAÇÕES FINAIS}

Podemos concluir que as equações do NDVI, foi de fundamental importância, para identificar as áreas degradadas, áreas saudáveis e áreas em processo de degradação. Todas as análises, foram possíveis apenas com as ferramentas de Geoprocessamento e Sensoriamento Remoto, que foram de fundamental importância, para a realização da referida pesquisa. Com o auxílio dos SIG's, foi possível realizar todos os processamentos dos dados, já com o auxílio dos sensores remotos foi possível extrair informações e transforma-las em dados reais, assim, classificando, quantificando e identificando todo o estado da cobertura vegetal da bacia analisada.

Com a presente pesquisa, referente a 19 anos de análise, foi identificado o aumento do solo exposto, a diminuição da cobertura vegetal e a troca, da vegetação esparsa e vegetação densa, pelos pastos, lavouras e pelos loteamentos, presente em grande parte da bacia. $\mathrm{O}$ mau uso dos recursos naturais, em destaque, a cobertura vegetal, acarretam inúmeros problemas para o meio ambiente, e a presente pesquisa, tenta colaborar para que o poder público, teça políticas para preservar os recursos naturais que estão presentes na bacia hidrográfica, para que haja um manejo e a utilização correta e consciente dos recursos da natureza, principalmente da cobertura vegetal, que influencia em todos os outros recursos, incluindo a recarga dos aquíferos presentes na bacia, e a vazão, que com a diminuição dos recurso florestais, tem um alto pico.

\section{REFERÊNCIAS}

CÂMARA, G.; DAVIS, C.; MONTEIRO, A. M. V. (org). Introdução à Ciência da Geoinformação. Disponivel em: http://www.dpi.inpe.br/gilberto/livro/introd. Acesso em: 17/09/2015.

DREW, D. Processos Interativos Homem-Meio Ambiente. 3. ed. São Paulo - SP: DIFEL, 1983.

FITZ, P. R. Geoprocessamento sem complicação. 1. ed. São Paulo: Oficina de Textos, 2008.

GOMES, D. D. M. Análise da degradação da cobertura vegetal da bacia hidrográfica do Rio Jaibaras / CE por meio de ferramentas de Geoprocessamento e Sensoriamento Remoto. Monografia (Especiliazação em Geoprocessamento) Universidade Estadual do Ceará. Fortaleza, p. 95. 2010. 
GOMES, D. D. M. Geoprocessamento aplicado a análise da vunerabilidade à erosão na bacia hidrográfica do Rio Jaibaras - Ceará. Dissertação de mestrado apresentado ao Programa de PósGraduação em Geologia da Universidade Federal do Ceará - UFC, 2011. 132 p.

GOMES, D. D. M. Geoprocessamento aplicado à análise e zoneamento dos Sistemas Ambientais da bacia Hidrográfica do Rio Mundaú - PE/AL. Tese de doutorado apresentado ao Programa de PósGraduação em Geologia da Universidade Federal do Ceará - UFC, 2015. 240 p.

PONZONI, F. J.; SANTOS, S. B. D.; CANTINHO, R. Z. Comparação entre índices de vegetação gerados a partir de dados dos sensores MODIS e Vegetation-2. Anais XVI Simpósio Brasileiro de Sensoriamento Remoto - SBSR, Foz do Iguaçú - PR, 13 a 18 abril 2013. 3023-3030.

ROSA, R. Introdução ao Sensoriamento Remoto. 7. ed. Uberlândia-MG: EDUFU, 2009.

TROPPMAIR, H. Biogeografia e Meio Ambiente. 8. ed. Rio Claro - SP: DIVISA, 2008.

\section{AGRADECIMENTOS}

Os autores agradecem a Universidade de Pernambuco (UPE) pelo financiamento dos recursos dos projetos de pesquisa "Diagnóstico geoambiental das bacias hidrográficas do Estado de Pernambuco: geoprocessamento aplicado ao manejo e conservação dos recursos naturais", junto ao Programa de Fortalecimento Acadêmico (PFA/IC), e ao Laboratório de Geoprocessamento e Modelagem Ambiental pela cessão dos dados cartográficos vetorizados e imagens de satélites.

Recebido em: 14/08/2016

Aceito para publicação em: 01/10/2016 